\title{
Mikroimmunoelektrophoresen auf Membranfolien Brauchbarkeit und Anwendung in der klinischen Routinediagnostik
}

\author{
Von W. Grabner, E. Morhard und G. Berg \\ Aus der Medizinischen Klinik mit Poliklinik der Universität Erlangen-Nürnberg (Direktor: Prof. Dr. L. Demling)
}

(Eingegangen am 8. Juni 1968)

In der vorliegenden Arbeit wird eine Mikromethode für immunoelektrophoretische Analysen von Proteinen auf Acetatfolien beschrieben. Ihre Brauchbarkeit für die klinische Routinediagnostik wird anhand von Beispielen demonstriert,

\section{Microimmunoelectrophoresis on membranes. Suitability and use in routine clinical diagnosis}

A micromethod is described for the immunoelectrophoretic analysis of proteins on acetate membranes. Its application to routine clinical diagnosis is demonstrated with examples.

Die Immunoelektrophorese gewinnt auf Grund ihrer differenzierten Aussagefähigkeit in der modernen Laboratoriumsdiagnostik zunehmend an Bedeutung.

Mit Entdeckung der Celluloseacetatfolie wurde ein neues Trägermaterial mit optimalen Trenneigenschaften und vielseitigen Anwendungsmöglichkeiten gefunden. Ihre Anwendung erstreckt sich gegenwärtig vorwiegend auf die quantitative Serumelektrophorese.

Deshalb soll gezeigt werden, daß Celluloseacetatfolien auch für Immunoelektrophoresen geeignet sind (1, 2, 3, 4). Ihre Vorteile gegenüber anderen Trägermedien rechtfertigen die Einführung in die immunologische Diagnostik. Daß die Anwendung von Acetatfolien noch keine allgemeine geworden ist, dürfte in erster Linie auf den vermeintlich hohen Kostenaufwand und auf Schwierigkeiten der Arbeitstechnik zurückzuführen sein $(4,5)$. Deshalb wurde eine für klinische Routineuntersuchungen brauchbare Mikrotechnik auf Folienkleinformaten entwickelt, über die im folgenden berichtet wird.

\section{Material und Methodik}

\section{Tränken der Acetatfolie in Pufferlösung}

Man läßt die Folien (Sartorius-Membranfolien: Format $57 \times 145$ $\mathrm{mm}$ ) mittels zweier Deckglaspinzetten flach auf die Pufferlösung (Barbituratpuffer, pH 8,6; Ionenstärke 0,037) fallen. Durch kapillaren Sog werden sie von unten benetzt. Nach vollständiger Durchtränkung müssen die Celluloseacetatstreifen in die Lösung eingetaucht werden.

\section{Abtrocknen der Acetatfolie}

Die dem Barbituratpuffer wieder entnommenen Membranfolien werden vorsichtig $z$ wischen 2 Filterblättern getrocknet. Es ist besonders darauf zu achten, daß die Streifen nur von überschüssigem Puffer befreit werden. Allein unter dieser Bedingung resultiert ein optimaler Feuchtigkeitsgrad. Zu starkes Trocknen ist streng zu vermeiden!

\section{Markierung der Antiserumdepots}

Sobald die Acetatfolie von überschüssiger Feuchtigkeit befreit ist, werden mit Hilfe eines Membranprägestempels (Hersteller: Beckman Instruments $\mathrm{GmbH}$, München) die Auftragerinnen für das Antiserum markiert.

\section{Einlegen der Folie in die Elektrophoresekammer}

Die Streifen werden auf einer Trägerbrücke gespannt, nachdem die Befestigungsstifte in die Lochreihen der Folien eingerastet sind.
Beim Einsetzen der Trägerbrücke in die Elektrophoresekammer (Mikrozone Elektrophoresis Cell; Hersteller: Beckman Instruments $\mathrm{GmbH}$, München) ist darauf zu achten, daß die Membranenden frei in die oben angegebene Pufferlösung eintauchen, ohne die Kammerwandung zu berühren.

\section{Auftragen der Serumprobe}

Zur Markierung der Albuminfraktion wird die Serumprobe im Verhältnis 10:1 mit 0,2proz. Bromphenolblaulösung versetzt. $5 \mu l$ dieser Verdünnung werden auf einen Spezialauftragestempel (Hersteller: Beckman Instruments) gebracht und als kreisförmige Fläche auf der Folie deponiert. Es ist zweckmäßig, den Reiter des Stempels in die vordere Führungsrinne der Kammer einzusetzen. Für Vergleichszwecke sollten 2 Serumproben aufgetragen werden. Membranprägestempel mit 4 Antiserumrinnen gestatten sogar das Auftragen von drei Proben.

\section{Elektrophoretische Trennung}

Die besten Trennungen wurden unter Beachtung folgender Bedingungen erzielt:

$\begin{array}{ll}\text { Trennzeit } & : 50 \text { Min. } \\ \text { Gleichspannung } & : 270 \text { Volt } \\ \text { pH der Pufferlösung } & : 8,6 \\ \text { Ionenstärke } & : 0,037 \\ \text { Umger } & : 22^{\circ}\end{array}$

Umgebungstemperatur : $22^{\circ}$

\section{Auftragen des Antiserums}

Nach beendeter Trennung wird die Trägerbrücke der Kammer entnommen, und in die präparierten Rinnen werden jeweils $30 \mu l$ Antiserum pipettiert. Am besten bewährt hat sich IEP-Antiserum vom Pferd. (Hersteller: Hyland Laboratories, Los Angeles, California USA).

\section{Immunodiffusion in der feucbten Kammer}

Die mit Antiserum beschickte Folie muß auf einem Folienträger gleichmäßig gespannt werden. Ein Durchhängen der Streifen ist auf alle Fälle zu vermeiden. Die Diffusionsdauer bei Raumtemperatur sollte mindestens $40 \mathrm{Stdn}$. betragen. Beim Auftragen dreier Serumproben verkürzt sich die Diffusionszeit um die Hälfte. Gute Ergebnisse werden bei der Immunodiffusion nur dann erzielt, wenn der Folienträger waagerecht in der feuchten Kammer steht. Bereits geringe Abweichungen von der horizontalen Lage führen zu mangelhạter Präzipitatbildung.

\section{Entfernung des nicht präzipitierten Eiwveißes}

Nach beendeter Immunodiffusion wird alles überschüssige Eiweiß von der Acetatfolie entfernt. Bewährt haben sich Spülungen in physiol. Natriumchloridlösung, die unter ständigem Badwechsel insgesamt $15 \mathrm{Min}$. durchzuführen sind. Es genügt, die Streifen während des Spülvorganges mit einer Pinzette hin und her zu bewegen. 


\section{Trockenen der Folien}

Nach Entfernung des nicht präzipitierten Eiweißes wird die Folie auf der Trägerbrücke im Trockenschrank bei einer Temperatur von $120^{\circ}$ getrocknet.

\section{Färben und Entfärben der Acetatstreifen}

Die getrockneten Folien läßt man flach auf die Färbelösung fallen (Amidoschwarz $10 \mathrm{~B}$ ). Nach ausreichender Benetzung werden sie cingetaucht. Die Färbedauer sollte $15 \mathrm{Min}$. betragen. Darauf werden die Folien in Methanol-Eisessig $(9: 1 \mathrm{v} / \mathrm{v})$ unter mehrfachem Badwechsel von überschüssigem Farbstoff befreit.

\section{Weiterbebandlung in Transparenzbad}

Nach ausreichender Entfärbung werden die Acetatstreifen für $1 \mathrm{Min}$. in $95 \mathrm{proz}$ Äthanol eingelegt und anschließend auf einer Glasplatte für $1 \mathrm{Min}$. im Transparenzbad (Äthanol-Eisessig 3:1 $\nabla / v)$ belassen.

\section{Trocknen der transparenten Folie}

Nach Entnahme aus dem Transparenzbad wird die Folie mit einer Gummischeibe blasenfrei auf der Glasplatte aufgezogen. Anschließend kommt der Streifen für 3 bis 4 Min. bei einer Temperatur von $120^{\circ}$ in den Trockenschrank.

\section{Ergebnisse}

Die beschriebene Mikrotechnik ist das Ergebnis zahlreicher Voruntersuchungen.

In 150 Einzelversuchen wurden die günstigsten Arbeitsbedingungen für die immunoelektrophoretischen Ana-

Ext.

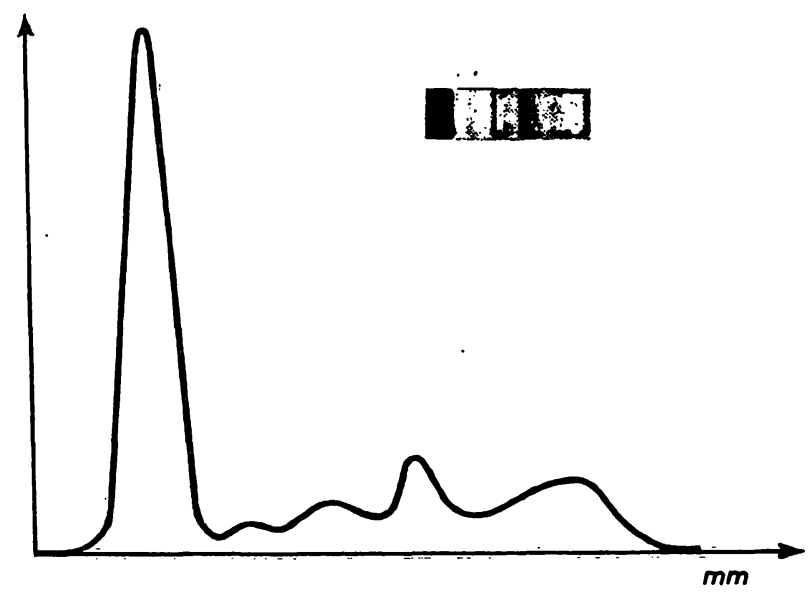

Abb. 1 a

Mikromembranfolienelektrophorese eines Normalserums. Trennzeit: 20 Min.; Gleichspannung: 250 Volt; Barbituratpuffer, $\mathrm{pH} 8,6$; Ionen-

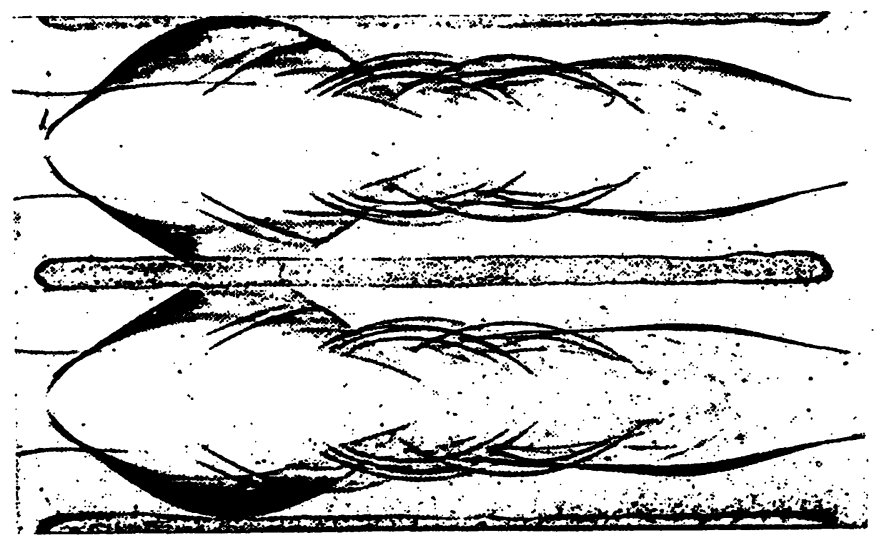

Abb. 1 b

Mikroimmunoelektrophorese des gleichen Serums bei Auftragen von 2 Proben (Vergrößerung: 1,25:1). Trennzeit: 50 Min.; Gleichspannung:
270 Volt; Barbituratpuffer, pH 8,6; Ionenstärke 0,037; Diffusionszeit: 270 Volt; Barbituratpuffer, pH 8,6; Ion lysen ermittelt. Ferner sollte die Brauchbarkeit der Methode für die klinische Routinediagnostik geprüft werden. Die vorliegenden Resultate beweisen, daß die angegebene Technik eine optimale Präzipitatbildung ermöglicht.

Die Qualität der immunoelektrophoretischen Analysen auf Membranfolien soll anhand der nachfolgenden Beispiele demonstriert werden (Abb. 1-4).

\section{Diskussion}

Für Immuneloektrophoresen gilt die Agartechnik als die Methode der Wahl. Deshalb wurden Celluloseacetatfolien bisher nur von wenigen Autoren (1- 6 ) für diese Zwecke geprüft. Zudem lassen die im Schrifttum veröffentlichten Arbeiten die Verwendung von Foliengroßformaten erkennen. Somit erschien es zweckmäßig, eine geeignete Mikromethode auf Kleinformaten zu entwickeln, denn allein ein geringer Kostenaufwand ist für klinische Routineuntersuchungen rentabel.

Die Vorteile gegenüber der gebräuchlichen Agarmethode sind nach KoHN und eigenen Erfahrungen folgende: Die Membranfolien sind stets gebrauchsfertig, die Präzipitationslinien zeichnen sich durch ihre größere Schärfe aus. Die Folien können für Dokumentationszwecke besser aufbewahrt werden als getrocknete Agar-

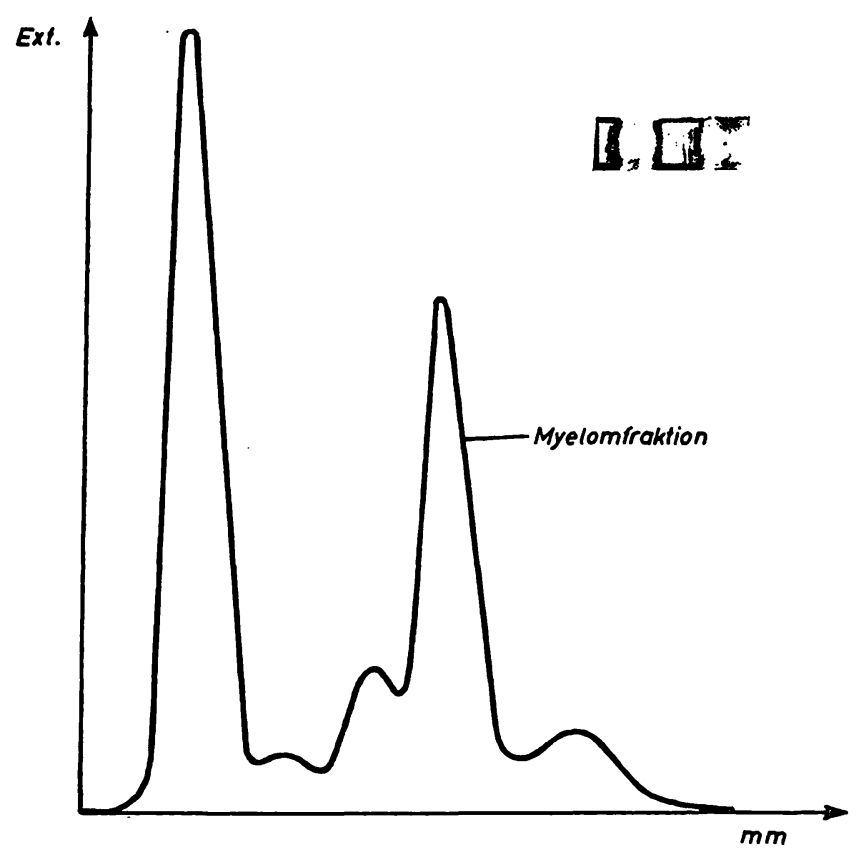

Abb. 2 a

Mikromembranfolienelektrophorese eines $\beta$-Myeloms. Versuchsbedingungen wie unter Abbildung I a

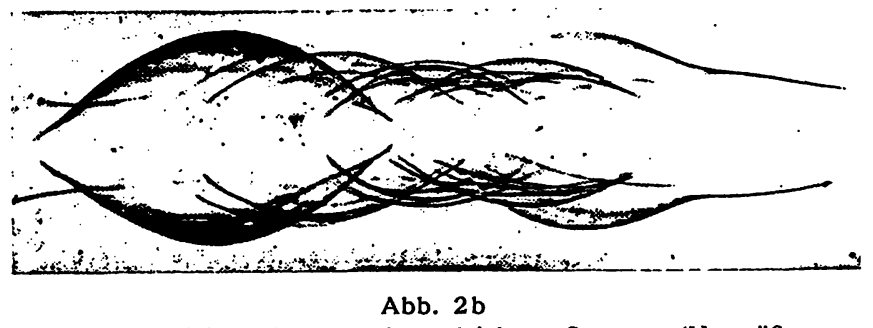

Mikroimmunoelektrophorese des gleichen Serums (Vergrößerung: $1,25: 1)$. Versuchsbedingungen wie unter Abbildung $1 \mathrm{~b}$ 


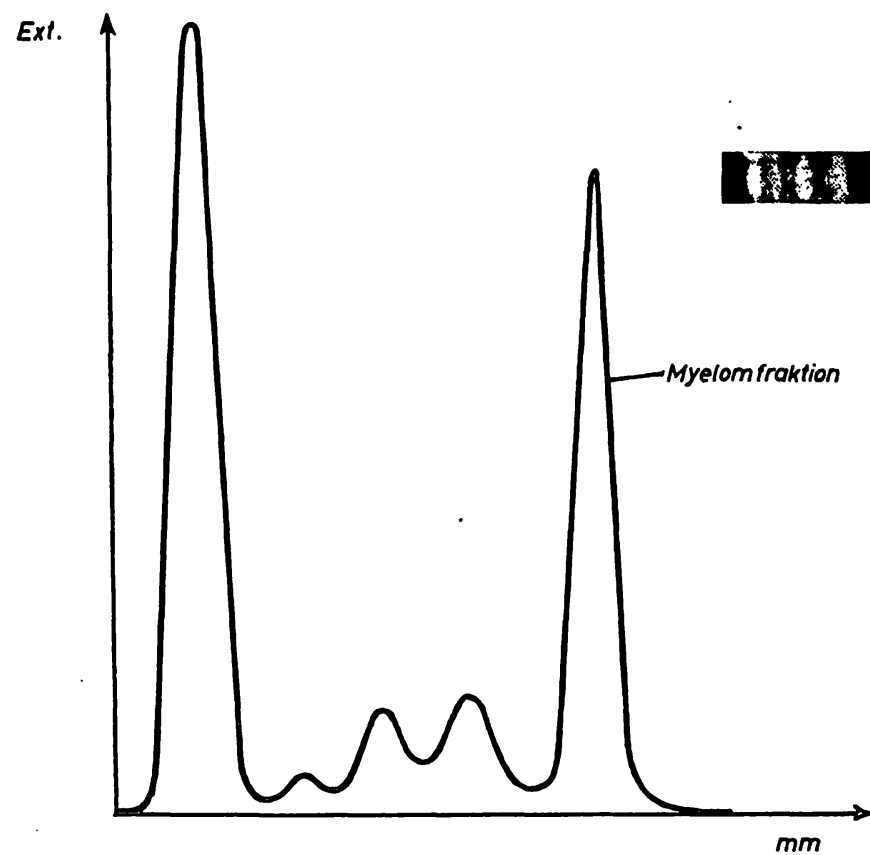

Abb. $3 a$

Mikromembranfolienelektrophorese eines $\gamma$-Plasmozytoms. Versuchsbedingungen wie unter Abbildung 1 a

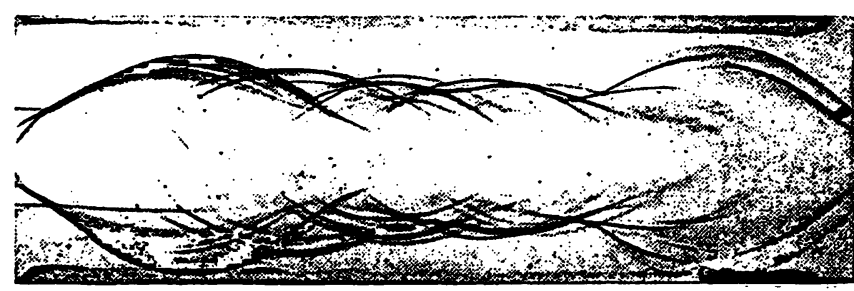

Abb. $3 b$

Mikroimmunoelektrophorese des gleichen Serums (Vergrößerung: $1,25: 1)$. Versuchsbedingungen wie unter Abbildung $1 \mathrm{~b}$

streifen $(1,4)$. Ein weiterer Vorzug der'beschriebenen Mikrotechnik ist die Zeitersparnis bei der Durchführung $(1,4,6)$.

Die Beurteilung immunoelektrophoretischer Analysen darf sich jedoch nicht auf Vergleiche mit Ergebnissen

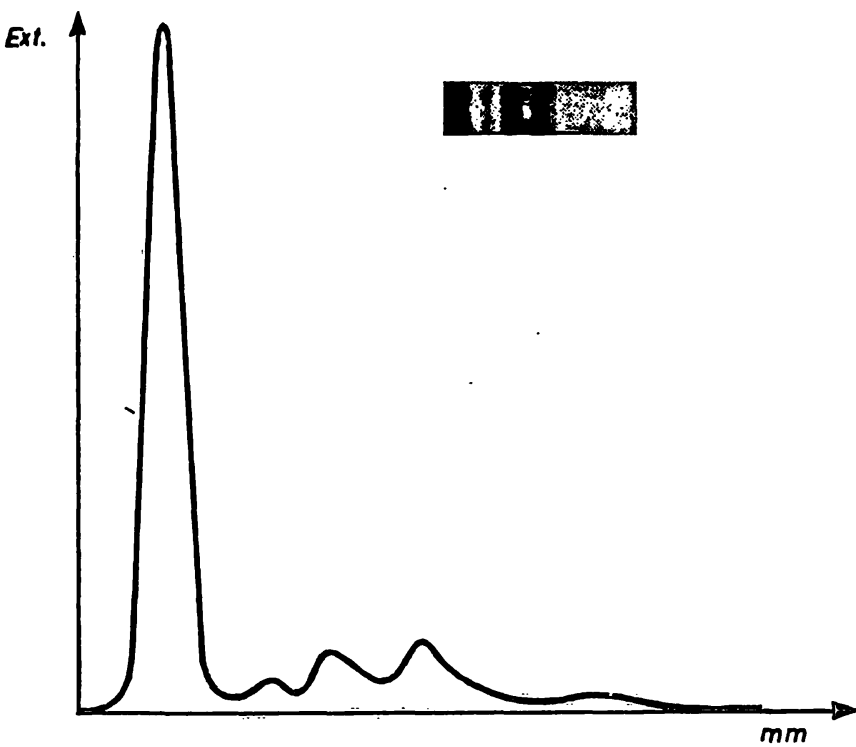

Abb. $4 a$

Mikromembranfolienelektrophorese eines Antikörpermangelsyndroms Versuchsbedingungen wie unter Abbildung 1 a

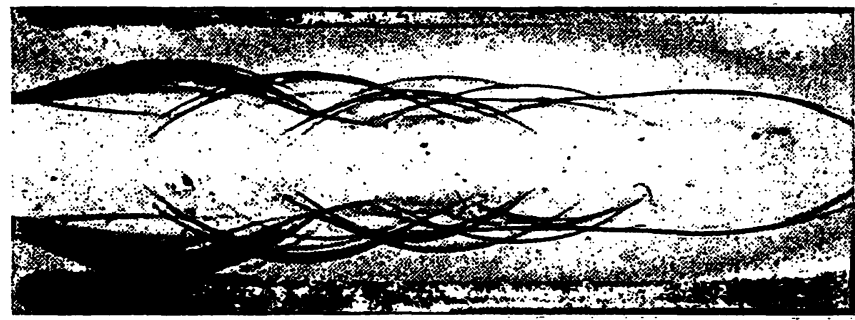

Abb. $4 \mathrm{~b}$

Mikroimmunoelektrophorese des gleichen Serums (Vergrößerung: 1,25:1) Versuchsbedingungen wie unter Abbildung 1 b

der Agartechnik stützen (4). Zur kritischen Interpretation der Befunde müssen normale Antigenverteilungsmuster herangezogen werden, wie sie sich bei der Folienelektrophorese mit nachfolgender Immunodiffusion ergeben (4). Die Ergebnisse sind jederzeit reproduzierbar.

\section{Literatur}

1. KoHN, J., Nature, London 180,986 (1957). - 2. Consden, R. und J. Kohn, Nature, London 183, 1512 (1959). - 3. Nelson, T. L., G. Stroup und R. Weddell, Amer. J. Clin. Path. 42, 237 (1964). - 4. Berg, G. und W. Grabner, Clin. Chim. Acta,
(Amsterdam) 17, 265 (1967). - 5. SüDHoF, H. und B. WALTER, Clin. chim. Acta (Amsterdam) 8, 434 (1963). - 6. Grunbaum, B. und L. LoNG, Nature (London) 194, 185 (1962).

\section{Dr. W. Grabner,} 852 Erlangen,

Medizinische Universitätsklinik, Krankenhausstraße 12 